Original Russian Text (C D.P. Kovalev, P.D. Kovalev, M.O. Khuzeeva, 2020, published in MORSKOY GIDROFIZICHESKIY ZHURNAL, Vol. 36, Iss. 1 (2020)

\title{
Features of Meteotsunami at the Capes of the Kuril Islands Urup and Kunashir
}

\author{
D. P. Kovalev ${ }^{I}$, Peter D. Kovalev ${ }^{1 *}$, M. O. Khuzeeva ${ }^{2}$ \\ ${ }^{1}$ Institute of Marine Geology and Geophysics, Far Eastern Branch of Russian Academy of Sciences, \\ Yuzhno-Sakhalinsk, Russian Federation \\ ${ }^{2}$ Sakhalin Hydrometeorological Service of Federal Service of Russia for Hydrometeorology \\ and Environmental Monitoring, Yuzhno-Sakhalinsk, Russian Federation \\ *kovalev_pd@outlook.com
}

Purpose. The aim of the present work is to study the features of the sea level oscillations with the periods characteristic of tsunami waves nearby the capes of Urup and Kunashir islands using in situ observations, to determine the range of the Froude number values which meteorological tsunami are generated at, and to scrutinize resonance features of the water areas for defining possibility of meteotsunami amplification.

Methods and Results. The time series of the waves obtained in the Institute of Marine Geology and Geophysics, Far East Branch of Russian Academy of Sciences in 2008 and 2009 by the instruments installed in the coastal area of the capes Castricum, Van der Lind and Lovtsova at the southern Kuril Islands - Kunashir and Urup, as well as the synoptic maps provided by the Sakhalin Hydrometeorological Service of Federal Service of Russia for Hydrometeorology and Environmental Monitoring were used. To assess potential danger of the meteorological tsunami, considered were the resonance features of the water areas where the instruments were installed. It was shown that passage of the atmospheric disturbance along the Kuril Islands was accompanied by generation of the sea level anomalous oscillations just in the places where the wave recorders were installed. According to the criterion calculated by the root-mean-square background level, the observed event could be identified as a meteorological tsunami. The range of the Froude numbers was determined; it showed that moving at the velocity within the above-mentioned range, the atmospheric disturbance under consideration could generate meteorological tsunami in the coastal zone of the islands. It was revealed that the $\mathrm{q}$ - factor of the resonance system was the highest in Cape Lovtsova: in case of arrival of the waves, the oscillations of which were close to the resonance system eigen oscillation, the amplification factor could reach 19.1.

Conclusions. Arrival of the sea waves of considerable amplitude whose oscillation is close to the resonance system eigen oscillation, can be followed by generation of dangerous waves. At that, if the Froude number value is close to 1 , the sea waves, according to the mechanism described by Proudman, can be continuously pumped with atmospheric energy. As a result, the forced sea wave becomes significantly amplified and dangerous.

Keywords: meteotsunami, seiches, waves, atmospheric disturbances.

Acknowledgements: the work was carried out within the framework of the state task of the Institute of Marine Geology and Geophysics, Far Eastern Branch of Russian Academy of Sciences.

For citation: Kovalev, D.P., Kovalev, P.D. and Khuzeeva, M.O., 2020. Features of Meteotsunami at the Capes of the Kuril Islands Urup and Kunashir. Physical Oceanography, [e-journal] 27(1), pp. 37-47. doi:10.22449/1573-160X-2020-1-37-47

DOI: $10.22449 / 1573-160 X-2020-1-37-47$

(C) D.P. Kovalev, Peter D. Kovalev, M.O. Khuzeeva, 2020

(C) Physical Oceanography, 2020

Introduction. Long waves registered in the ocean are excited by various sources, mainly such as underwater seismic vibrations or atmospheric disturbances. In the coastal zone, having resonance properties, these waves, in turn, can excite seiches of large amplitude. Periods of these waves will be determined exclusively 
by local topography and their amplitude by the quality factor of the coastal resonance system.

Generated by atmospheric disturbances (baric gravitational waves, pressure surges, cold fronts and other types of disturbances), sea barotropic waves are amplified in the coastal zone in accordance with the mechanisms described in [1-3]. It can be said that sea waves observed in the coastal zone owe their origin to a combination of bathymetry and atmospheric influences.

Periods of such sea level oscillations can vary from a few minutes to several hours. Typically, in the case of meteorological tsunamis, a range of wave periods from 2 minutes to 2 hours is considered, corresponding to the range of periods of seismic tsunami waves. These are waves with minute periods and characteristic spatial scales of about $50 \mathrm{~km}$. Synoptic atmospheric disturbances have an order of magnitude greater spatial scales and daily periods and are poorly consistent with the observed high-frequency variability of sea level [3]. Therefore, the atmospheric disturbances cannot be expected to excite directly the shorter sea level oscillations, since in baric waves the fraction of energy is small on the scales and periods necessary for the excitation of seiches [4].

At the same time, as shown in [5], atmospheric disturbances emit energy in the form of high-frequency gravity waves. Therefore, with the passage of baric gravity waves, the excitation of sea level oscillations with minute periods near the coast was observed in different places. These oscillations have different names, for example, Abiki in Japan, Rissag on the Balearic Islands and others. Later, the term "meteotsunami" was proposed to describe such oscillations, meaning their similarity to tsunami waves [6].

The present paper is aimed to study the characteristics of sea level oscillations near capes Castricum, Van der Lind on Urup Island and Lovtsova on Kunashir Island using data from field observations of the waves, carried out from 2008 to 2012. It should also be noted that the Institute of Marine Geology and Geophysics of the Far Eastern Branch of the Russian Academy of Sciences (IMGG FEB RAS) has been studying meteotsunamis for several years [7, 8].

Observational data. In this paper, the data from observations of sea level oscillations obtained using autonomous wave recorders that record with one second discreteness is used. They were installed in the area of capes Castricum and Van der Lind on Urup Island at depths of about 15 and $21.5 \mathrm{~m}$, respectively. The third instrument was installed in the area of Cape Lovtsova at about $25.5 \mathrm{~m}$ depth. The map of the region of the instruments is shown in Fig. 1. The distance between capes Castricum and Van der Lind is about $114 \mathrm{~km}$, and between capes Van der Lind and Lovtsova -- about $250 \mathrm{~km}$.

In addition to those described above, the instruments were installed in Kurilsk (Iturup Island) and in Tserkovnaya Bay. (Shikotan Island). However, since the power supply of these instruments is optimized for six months, and the ability to replace them on time was not always available, synchronous records obtained from three instruments were mainly used. 


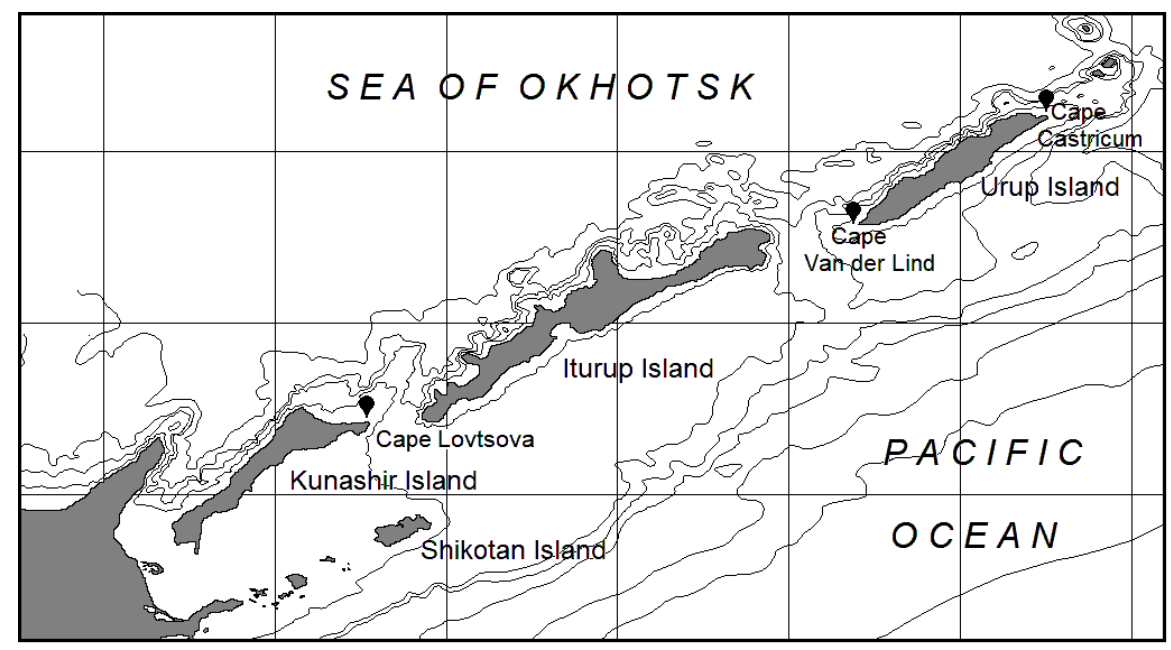

F i g. 1. Map of the region under observation and location of instruments

Samples of the synchronous records of sea level oscillations (waves) obtained in 2008 are shown in Fig. 2. Tidal motions are clearly visible, during the measurements several storms were observed with a wave height of up to $6 \mathrm{~m}$ in the area of Cape Castricum.

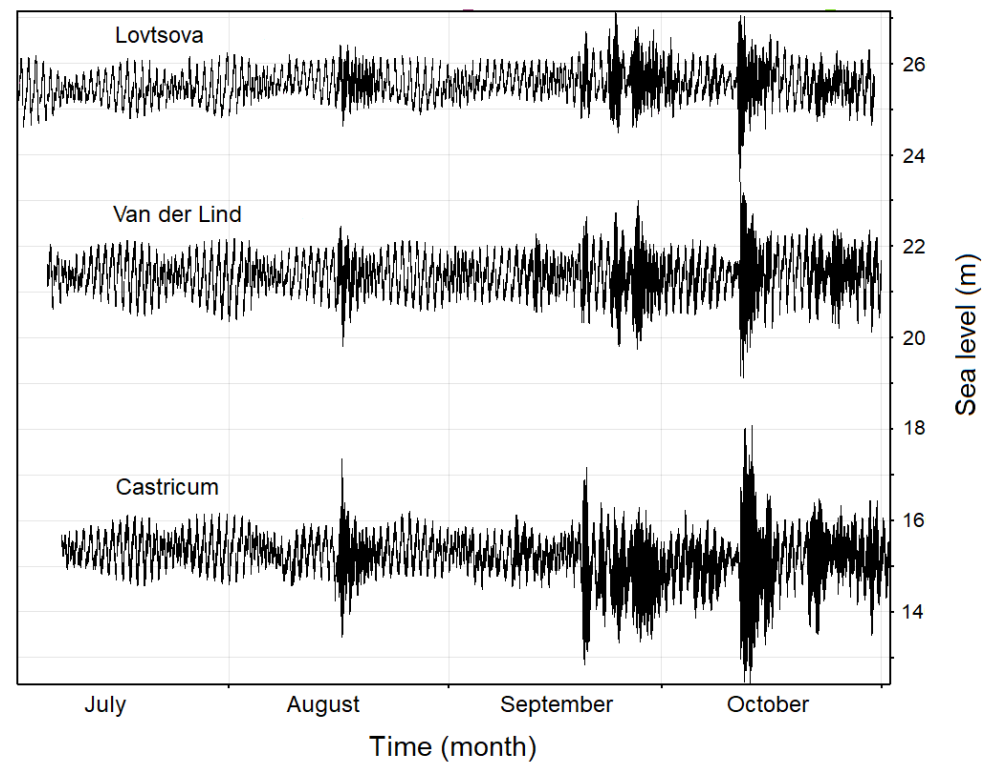

F i g. 2. Time series of sea level oscillations near capes Lovtsova, Van der Lind and Castricum

Observation data processing and analysis. Since the range of wave periods by meteorological tsunami is $2-120 \mathrm{~min}$, the precomputed tide was subtracted from the observational data, after which the series were filtered by a band-pass filter 
with a period range of 2-120 min. Based on the obtained time series, the spectrograms were calculated for three observation points (Fig. 3).
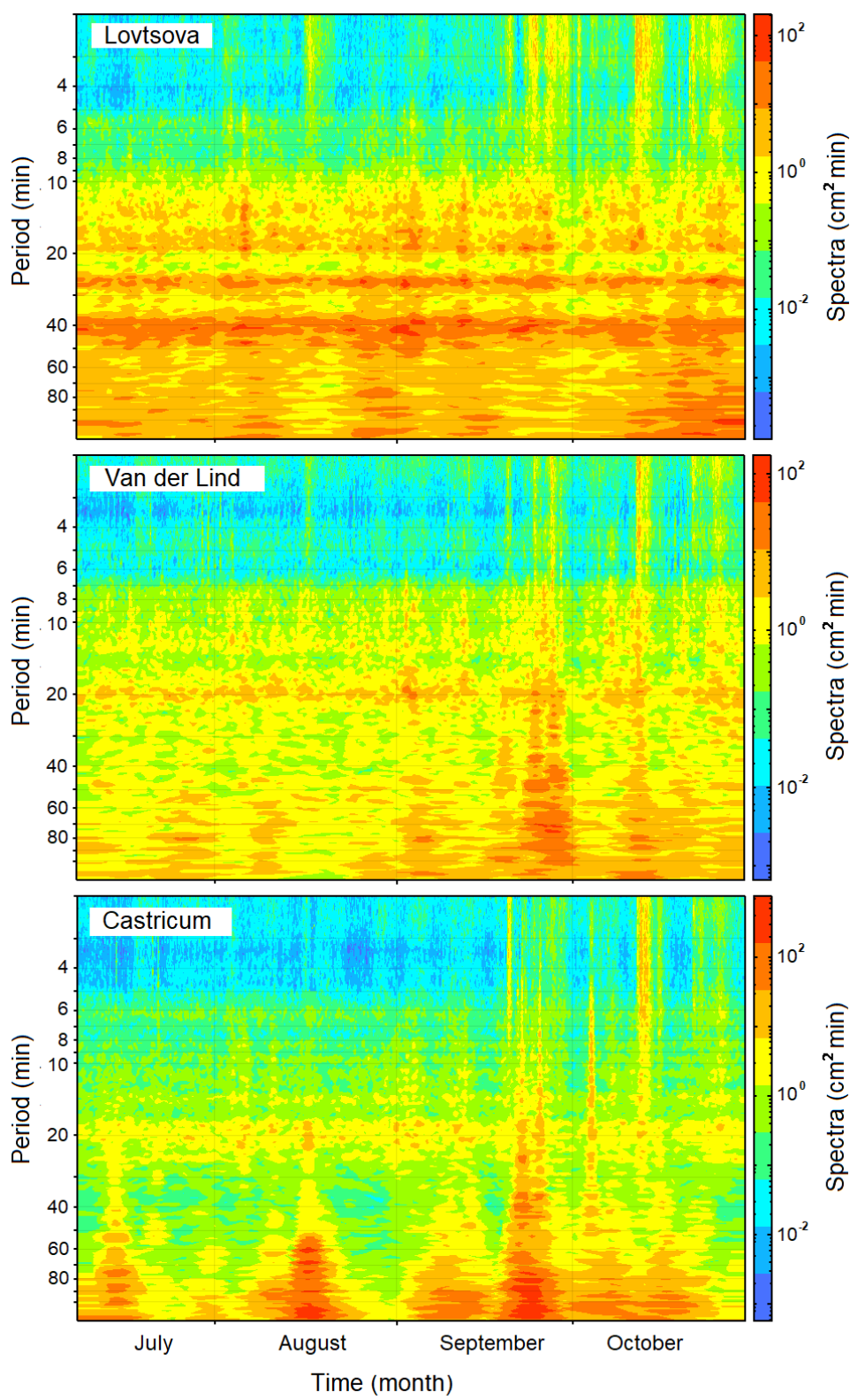

F i g. 3. Spectrograms of sea level oscillations within the period range $2 \mathrm{~min}-2 \mathrm{hrs}$

It was noted above that the amplification of waves occurs at the resonant frequencies of the water areas, therefore, the resonance periods at the points of installing the instruments were estimated from the spectra. In the area of capes Castricum and Van der Lind, the resonance periods were close to 19.8 minutes, and in the area of Cape Lovtsova, they were close to 18.2 minutes. It should be noted 
that, at Cape Lovtsova peaks were also observed at periods of approximately 32 and 40 minutes, but peaks in the oscillation spectra characteristic of three observation points were considered for comparison (Fig. 3).

Further, the residual series of level oscillations were analyzed to detect abnormal oscillations. A significant increase in the wave amplitude was revealed on August 5-6, September 2 and October 11-12, 2008. At the same time, the largest amplitudes were observed at the three stations on October 11-12, when the residual level oscillations reached $23 \mathrm{~cm}$ at Cape Castricum. This data further were used for analysis. Records of level oscillations and their spectra for the period under consideration are shown in Fig. 4.

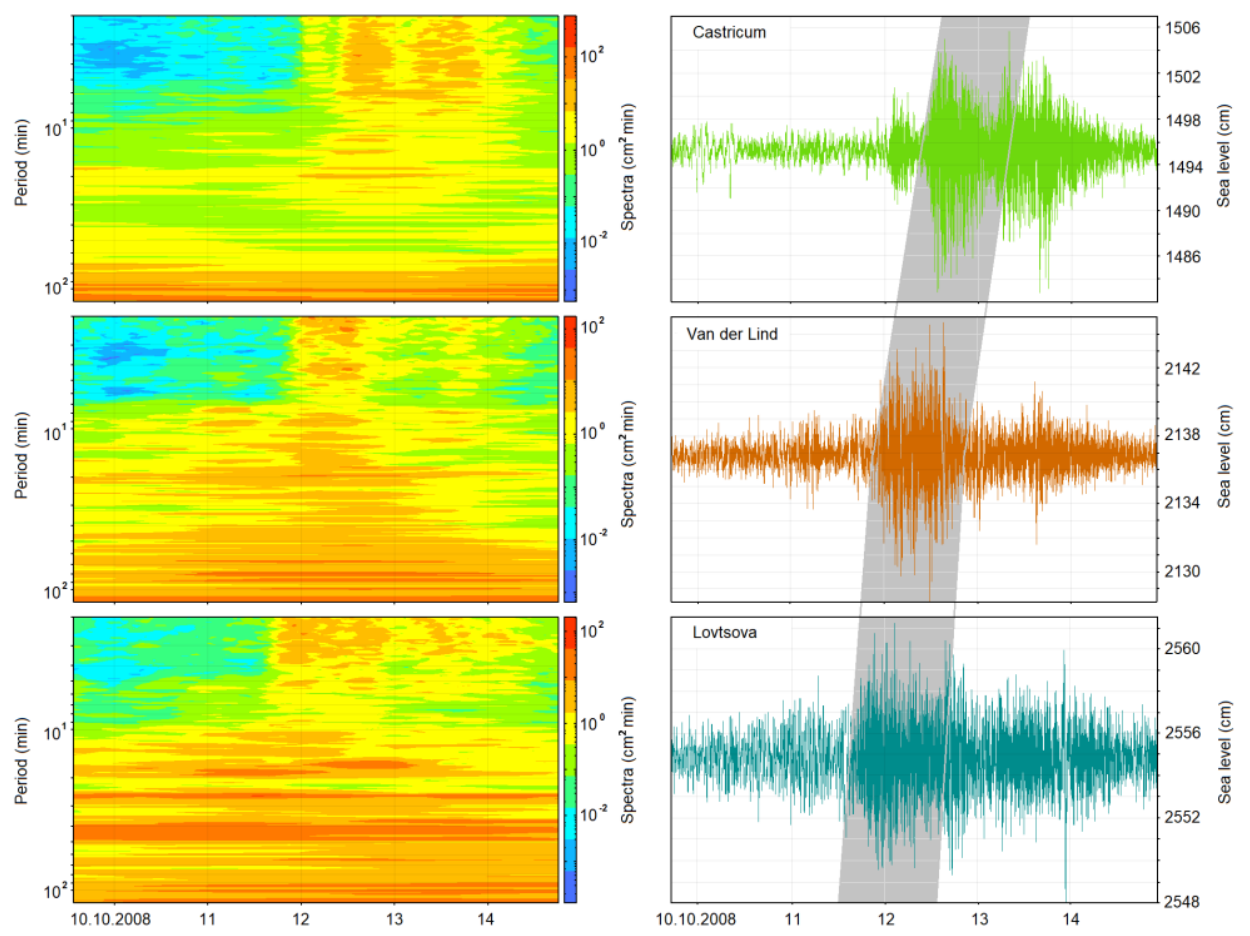

F i g. 4. Time series of sea level oscillations after subtraction of tide and band-pass filtering within the period range 2-120 min.; the spectrograms are for October 10-15, 2008. The shaded area approximately corresponds to the time periods when the sea level variability is significant in different places

The detected anomalous fluctuations are supposedly meteotsunamis, since about $99 \%$ of the background vibration energy in the sea in the range of tsunami periods is associated with atmospheric disturbances [6]. Nevertheless, not all sea level oscillations can be attributed to meteorological tsunami. In [6], it was proposed to use the wave amplitude as a criterion for the threshold by meteorological parameters, exceeding three or four times the rms value, defined by the following expression: 


$$
x_{\mathrm{rms}}=\sqrt{\frac{1}{n}\left(x_{1}^{2}+x_{2}^{2}+\ldots+x_{n}^{2}\right)},
$$

where $x_{1}, x_{2}, \ldots, x_{n}$ are amplitudes of background waves, and $n$ - their number, or use two criteria that take into account the absolute and relative wave heights.

The $x_{\text {rms }}$ value calculated for background amplitudes with a period of $20 \mathrm{~min}$ measured at Cape Castricum within two days is $1.12 \mathrm{~cm}$, while for an event the average amplitude with the same period is $7.67 \mathrm{~cm}$. Thus, the considered event can be attributed to meteorological tsunami. In this case, the energy of meteorological tsunamis is distributed over almost the entire range of periods of tsunami waves, apparently due to the fact that in the places where the instruments were installed, the resonance properties are manifested over several periods (Fig. 3).

Weather conditions were analyzed to determine the source of anomalous wave excitation using synoptic maps provided by the Sakhalin Hydrometeorological Center for Hydrometeorology and Environmental Monitoring. A weather map on October 11, 2008 at 6:00 UTC with the position of the cold front shown on it from 18:00 on October 10 to 18:00 on October 11 is shown in Fig. 5. It is completely obvious that only a cold front could initiate anomalous excitement, which on October 11 approached Cape Lovtsova. When approaching it, the front movement velocity towards Kuril Ridge, estimated from its position at different points in time, was about $45.3 \mathrm{~km} / \mathrm{h}$. Subsequently, the front advanced eastward, and its wing moved along the Kuril Ridge islands.

Since meteotsunami are associated with waves that interact with atmospheric pressure and absorb atmospheric energy during propagation [6], the propagation velocity of the cold front generating these waves was estimated from the time the anomalous wave started. So, the arrival of waves to Cape Lovtsova was observed at 16:58 on Oct. 11, 2008, to Cape Van der Lind - at 22:23 on Oct. 12, 2008, and to Cape Castricum - at 11:56 on Oct. 12, 2008. At the distances between the capes determined by the maps, the velocity of atmospheric disturbance movement in the section from Cape Lovtsova to Cape Van der Lind was about $46 \mathrm{~km} / \mathrm{h}$, i.e., taking into account the errors, it can be assumed that the values of the atmospheric disturbance movement velocity determined by the position of the front and the time of arrival of the waves coincide.

In the Cape Van der Lind - Cape Castricum section, the atmospheric disturbance movement velocity estimated from the start time of the anomalous wave is about $8.4 \mathrm{~km} / \mathrm{h}$ and about $28.7 \mathrm{~km} / \mathrm{h}$ in front movement velocity. The reason for this difference in estimates is not obvious and needs to be studied separately. It should be noted that the calculated velocities are average at the distances under consideration, and a decrease in the rate of atmospheric disturbances to the north of the Sea of Okhotsk is usually observed. 


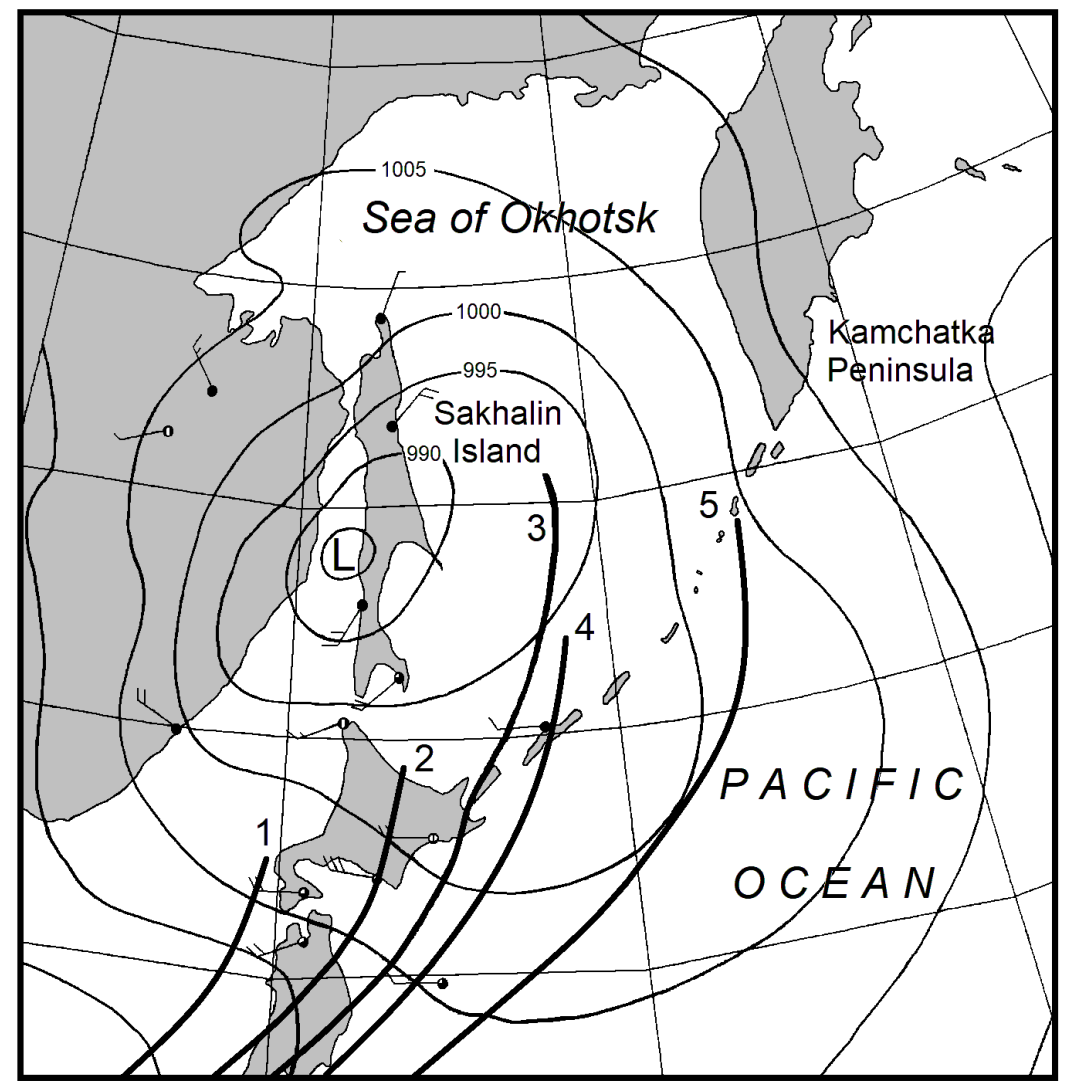

F i g. 5. Synoptic map for October 11, 2008, 6:00 UTC (based on the data of the Sakhalin Hydrometeorological Service of Federal Service of Russia for Hydrometeorology and Environmental Monitoring). Position of cold front 1 corresponds to October, 10, 18:00; the rest of the fronts (2-5) are represented with a $6 \mathrm{hr}$ lag

Considering the appearance of anomalous waves at different points, it should be borne in mind that this is not the same wave excited in the Cape Lovtsova area and propagating along the Kuril Ridge. The generation of anomalous oscillations is in good agreement with the passage of atmospheric disturbance, which "turns on" them as they move. In the records obtained at each point, oscillations prevail due to the local nature of the bottom topography and the topography of the coastline in the adjacent water areas. This is an important difference between meteorological tsunamis and tsunamis of seismic origin - they occur mainly locally [6, 8].

S. Montserrat et al. [6] believe that meteorological tsunamis are similar to tsunami waves generated by landslides. The parameters of such waves and their relation to the sliding landslide speed depend on the Froude number. For a solid moving with a velocity $U$, the Froude number is written as follows:

$$
\operatorname{Fr}=U / c
$$


where $c$ - local velocity of long waves [9, 10]. Resonance occurs when these velocities are equal, i.e., at $\mathrm{Fr}=1.0$. The nature of the generated waves varies significantly for the values of the Froude number $\mathrm{Fr} \neq 1.0$. For $\mathrm{Fr}<1.0$, perturbation does not cause waves propagating through the water [10].

To determine the Froude number values in the cases under consideration, it is necessary to calculate the propagation velocities of surface waves in the places where the instruments were installed. Given the depth at the places of installing the instruments (from $15 \mathrm{~m}$ at Cape Castricum to $25.5 \mathrm{~m}$ at Cape Lovtsova), for this range of depths, using the well-known formula for long waves, the range of phase wave velocities, ranging from 43.6 to $56,9 \mathrm{~km} / \mathrm{h}$ is determined. Moreover, the range of the Froude number values for these velocities, determined by expression (2) for the section from Cape Lovtsova to Cape Van der Lind, will be within the range of $1.057-0.810$. That is, when atmospheric disturbances move in the coastal zone of islands with depths of 15 to $25.5 \mathrm{~m}$, sea waves can be generated. For capes Van der Lind - Castricum, the range of the Froude number is 0.193-0.148. Thus, it is confirmed that the considered atmospheric disturbance moving with the indicated velocities can generate meteotsunami at $U \sim c$ and Fr $\sim 1.0$ (corresponds to the section from Cape Lovtsova to Cape Van der Lind) and continuous energy pumping can occur into sea waves, that is, there is a Proudman resonance [2], while the forced sea wave is significantly amplified.

It should also be noted that sea waves generated by atmospheric disturbances can reach significant amplitudes only if there is a local or regional topographic resonance in the coastal zone [6]. At the same time, external waves with large amplitudes are not enough to generate seiches in the resonance water area. Dangerous seiches can only be generated in the water area with well-defined resonant properties, having a high $\mathrm{Q}$ factor (Q-factor) [11]. In this case, the amplification of the long waves arriving in the resonance water area can be represented by the approximating expression as follows

$$
H^{2}(f)=\frac{1}{\left(1-f / f_{0}\right)^{2}+\mathrm{Q}^{-2}\left(f / f_{0}\right)^{2}},
$$

where $f$ is the frequency of the long waves; $f_{0}$ is the harbor resonance frequency; Q is the quality factor of a resonant system [11]. At the resonance $f=f_{0}$, and power amplification factor reaches the value of $\mathrm{Q}^{2}$.

Using the spectra, the quality factors of the resonant systems were calculated at the places where the instruments were installed, and the expression factor (3) was used to calculate the amplification of the incoming waves depending on their frequency (Fig. 6). It can be seen that the higher quality factor of the system is for Cape Lovtsova (equal to 4.25), at which the amplification in the case of arrival of waves with frequencies close to the own frequency of the resonance system reaches 19.1. When the sea waves reach the significant amplitude, significant wave amplification can be expected. 


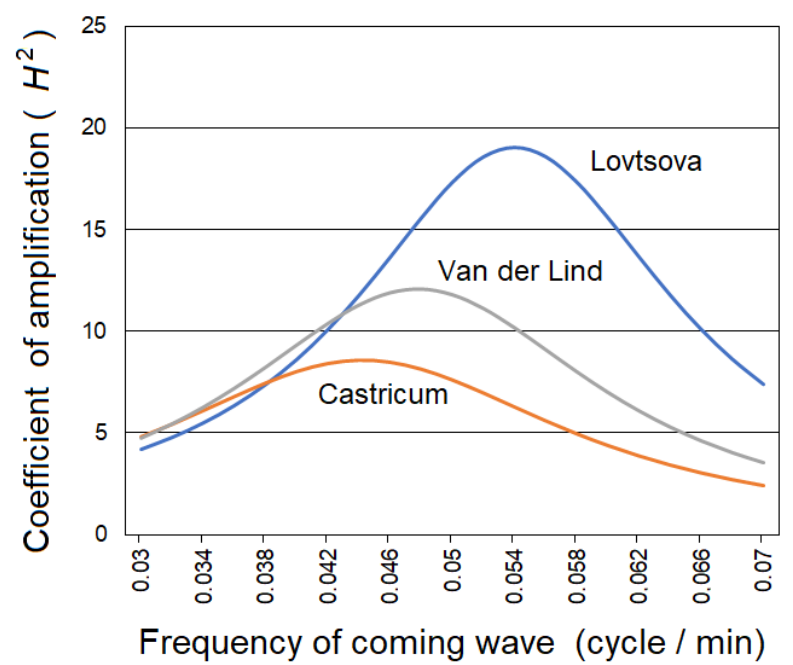

F i g. 6. The amplification coefficient versus frequency for coming wave

However, since several factors must be present, namely, a high-energy atmospheric disturbance, the corresponding resonant bathymetry of the open ocean and the shelf, the direction and velocity of the atmospheric disturbance - and the probability of their coincidence is small, and then the occurrence of dangerous waves is rare and limited to specific locations. The high risk of meteorological tsunami in these places is determined by a combination of shelf topology and coastline geometry, creating a double resonance effect [12].

Conclusion. The present paper considers a study of the possibility of generating meteorological tsunami during the passage of atmospheric disturbances over the regions of three capes of the large islands of the Kuril Ridge - Kunashir and Urup, using long-term records of sea level oscillations obtained in IMGG in 2008 and 2009, and based on their analysis in the range of wave periods tsunami - from 2 to 120 minutes. Synoptic maps provided by the Sakhalin Hydrometeorological Service were also used.

It was found that when an atmospheric disturbance passes along the Kuril Islands in the area of capes Castricum, Van der Lind, and Lovtsova, anomalous fluctuations of sea level are generated in the range of periods characteristic of tsunamis in places where wave meters are installed. The estimated threshold criteria for meteotsunami events October 11-12, 2008, and shows that it belongs to the category of meteotsunami.

The range of Froude number values, which is $1.057-0.810$, is determined for the velocity of atmospheric disturbance movement of approximately $46.1 \mathrm{~km} / \mathrm{h}$ in the section from Cape Lovtsova to Cape Van der Lind and surface wave velocities in the coastal zone with depths from 15 to $25.5 \mathrm{~m}$. This means that in almost the entire range of considered atmospheric disturbance velocity values in the coastal zone of the islands, it is possible to generate sea waves. Given that in the range of Froude number values there are values approximately equal to unity, atmospheric disturbances can generate sea waves, continuously pumping energy 
into them in accordance with the mechanism described by Proudman, as a result of which the forced sea wave is significantly amplified and can be dangerous.

Since, as noted in [6], tsunami-like waves generated by atmospheric disturbances can reach potentially dangerous levels only if there is a local or regional topographic resonance, from the calculated spectra the quality factor of the resonance systems at the locations of the wave meters and the amplification factor for long waves coming to the resonant water area from the open sea is calculated. The highest quality factor of the system at Cape Lovtsova (equal to 4.25), at which the amplification factor in the case of coming of waves with frequencies close to the own frequency of the resonance system reaches 19.1. Therefore, with the arrival of sea waves of significant amplitude and close in frequency to the own frequency of the resonant system, the generation of dangerous waves can be expected.

\section{REFERENCES}

1. Greenspan, H.P., 1956. The Generation of Edge Waves by Moving Pressure Distributions. Journal of Fluid Mechanics, 1(6), pp. 574-592. https://doi.org/10.1017/S002211205600038X

2. Proudman, J., 1929. The Effects on the Sea of Changes in Atmospheric Pressure. Geophysical Supplements to the Monthly Notices of the Royal Astronomical Society, 2(4), pp. 197-209. https://doi.org/10.1111/j.1365-246X.1929.tb05408.x

3. Mehra, P., Prabhudesai, R.G., Joseph, A., Kumar, V., Agarvadekar, Y., Luis, R. and Viegas, B., 2012. A Study of Meteorologically and Seismically Induced Water Level and Water Temperature Oscillations in an Estuary located on the West Coast of India (Arabian Sea). Natural Hazards and Earth System Sciences, 12(5), pp. 16071620. https://doi.org/10.5194/nhess-12-1607-2012

4. Candela, J., Mazzola, S., Sammari, C., Limeburner, R., Lozano, C.J., Patti, B. and Bonanno, A., 1999. The "Mad Sea" Phenomenon in the Strait of Sicily. Journal of Physical Oceanography, 29(9), pp. 2210-2231. https://doi.org/10.1175/15200485(1999)029<2210:TMSPIT>2.0.CO;2

5. Monserrat, S. and Thorpe, A.J., 1992. Gravity-Wave Observations Using an Array of Microbarographs in the Balearic Islands. Quarterly Journal of the Royal Meteorological Society, 118(504), pp. 259-282. https://doi.org/10.1002/qj.49711850405

6. Monserrat, S., Vilibić, I. and Rabinovich, A.B., 2006. Meteotsunamis: Atmospherically Induced Destructive Ocean Waves in the Tsunami Frequency Band. Natural Hazards and Earth System Sciences, 6(6), pp. 1035-1051. https://doi.org/10.5194/nhess-6-1035-2006

7. Kovalev, D.P., Shevchenko, G.V. and Kovalev, P.D., 2015. Propagation of Meteotsunami off the Seashore of Sakhalin Island. In: B.V. Levin and O.N. Likhacheva, eds., 2015. Geodynamical Processes and Natural Hazards. Lessons of Neftegorsk: International scientific conference, Yuzhno-Sakhalinsk, 2630 May, 2015: Proceedings. In 2 vol. Vladivostok: Dalnauka, Vol. 1, pp. 312-316 (in Russian).

8. Kovalev, P.D., Shevchenko, G.V., Kovalev, D.P. and Shishkin, A.A., 2017. Meteotsunamis on Sakhalin and the South Kuriles. Vestnik of the Far East Branch of the Russian Academy of Sciences, (1), pp. 79-87 (in Russian). 
9. Pelinovsky, E. and Poplavsky, A., 1996. Simplified Model of Tsunami Generation by Submarine Landslides. Physics and Chemistry of the Earth, 21(1-2), pp. 13-17. https://doi.org/10.1016/S0079-1946(97)00003-7

10. Fine, I.V., Rabinovich, A.B., Thomson, R.E. and Kulikov, E.A., 2003. Numerical Modeling of Tsunami Generation by Submarine and Subaerial Landslides. In: A.C. Yalçiner, E.N. Pelinovsky, E. Okal and C.E. Synolakis, eds., 2003. Submarine Landslides and Tsunamis. NATO Science Series (Series IV: Earth and Environmental Sciences), Vol. 21. Dordrecht: Springer, pp. 69-88. https://doi.org/10.1007/978-94-010-0205-9_9

11. Raichlen, F., 1966. Harbor Resonance. In: A.T. Ippen ed., 1966. Estuary and Coastline Hydrodynamics. New York: McGraw-Hill, pp. 281-340.

12. Rabinovich, A.B., 1993. Long Ocean Gravity Waves: Trapping, Resonance, and Leaking. Saint Petersburg: Hydrometeoizdat, 325 p. (in Russian).

About the authors:

Dmitry P. Kovalev, Leading Research Associate, Institute of Marine Geology and Geophysics, Far Eastern Branch of Russian Academy of Sciences (1b Nauki Str., Yuzhno-Sahalinsk, 693022, Russian Federation), Dr. Sci. (Phys.-Math), ORCID ID: 0000-0002-5184-2350, SCOPUS Author ID: 26032627700, ResearcherID: A-9300-2016, d.kovalev@imgg.ru

Peter D. Kovalev, Leading Research Associate, Institute of Marine Geology and Geophysics, Far Eastern Branch of Russian Academy of Sciences (1b Nauki Str., Yuzhno-Sahalinsk, 693022, Russian Federation), Dr. Sci. (Engineer.), ORCID ID: 0000-0002-7509-4107, SCOPUS Author ID: 16429135400, ResearcherID: V-8662-2018, p.kovalev@imgg.ru

Marina O. Khuzeeva, Head of the Department of Marine Hydrometeorology, Sakhalin Hydrometeorological Service of Federal Service of Russia for Hydrometeorology and Environmental Monitoring (State Budgetary Institution Sakhalin Environmental Monitoring Agency) (78, Zapadnaya St., Yuzhno-Sakhalinsk, 693000, Russian Federation), marina-khuzeeva@ rambler.ru

Contribution of the co-authors:

Dmitry P. Kovalev - development of methods and experimental studies; carrying out calculations; processing and description of the results of the study; formulation of conclusions

Peter D. Kovalev - literature review on the research;concept development; analysis of the mathematical models, formulation and statement of the problem; qualitative analysis of the results and their interpretation; formulation of conclusions

Marina O. Khuzeeva - literature review on the research problem; synoptic data processing

All the authors have read and approved the final manuscript.

The authors declare that they have no conflict of interest. 